\title{
Correction to: Combining Machine Learning and Qualitative Methods to Elaborate Students' Ideas About the Generality of their Model-Based Explanations
}

\author{
Joshua M. Rosenberg ${ }^{1} \cdot$ Christina Krist $^{2}$
}

Published online: 20 November 2020

C) Springer Nature B.V. 2020

Correction to: Journal of Science Education and Technology https://doi.org/10.1007/s10956-020-09862-4

The original version of this article inadvertently omitted the Acknowledgment section. That section is included below.

Acknowledgment This research was supported by National Science Foundation Grant DRL-1020316 to Northwestern University.

The original article can be found online at https://doi.org/10.1007/ s10956-020-09862-4.

Joshua M. Rosenberg jmrosenberg@utk.edu

1 University of Tennessee, 420 Claxton Complex, 1122 Volunteer Blvd, Knoxville, TN 37996, USA

2 University of Illinois Urbana-Champaign, Champaign, IL, USA 